\title{
WAVE MEASUREMENTS, NEEDS AND DEVELOPMENTS FOR THE NEXT DECADE
}

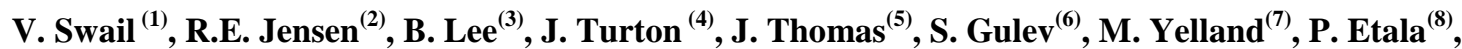

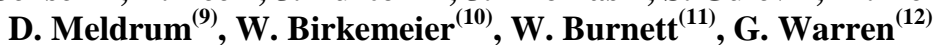 \\ (1) Environment Canada, 4905 Dufferin Street, Toronto, Ontario Canada M3H 5T4, Email: Val.Swail@ec.gc.ca \\ ${ }^{(2)}$ USACE/CHL (US Army Corps of Engineers/Coastal and Hydraulics Laboratory), 3909 Halls Ferry Rd. \\ Vicksburg, MS, USA, Email: Robert.E.Jensen@usace.army.mil \\ ${ }^{(3)}$ B. Lee, IOC UNESCO (Intergovernmental Oceanographic Commission of United Nations Educational, Scientific and \\ Cultural Organization), 1 rue Miollis 75732 Paris Cedex 15, France, Email: b.lee@ unesco.org \\ (4) Met Office, FitzRoy Road, Exeter EX1 3PB, United Kingdom, Email: jon.turton@metoffice.gov.uk \\ ${ }^{(5)}$ Scripps Institution of Oceanography, 9500 Gilman Drive, La Jolla, CA, USA, Email : jot@ucsd.edu \\ ${ }^{(6)}$ P.P. Shishov Inst of Oceanology RAS (Russian Academy of Sciences), 36 Nakhimovsky ave. 117997, \\ Moscow, Russia, Email: gul@sail.msk.ru \\ (7) National Oceanography Centre, Waterfront Campus, European Way, Southampton, SO14 3ZH, UK, \\ Email:M.Yelland@noc.ac.uk \\ (8) Servicio Meteorológico de la Armada, Av. Comodoro Py 2055, piso 15, 1104 Buenos Aires, Ciudad Autónoma de \\ Argentina, Email : etala@ara.mil.ar \\ ${ }^{(9)}$ Scottish Association for Marine Science, Dunstaffnage Marine Laboratory, Dunbeg, Oban, Scotland, PA37 1QA \\ United Kingdom, Email: dtm@sams.ac.uk \\ ${ }^{(10)}$ USACE/FRF (US Army Corps of Engineers/Field Research Facility), 1261 Duck Rd. Kitty Hawk, NC, USA, \\ Email: William.A.Birkemeier@usace.army.mil \\ ${ }^{(11)}$ NOAA (National Oceanic and Atmospheric Administration), National Data Buoy Center, 1007 Balch Blvd., \\ Stennis Space Center, MS 39529, USA, Email: Bill.Burnett@noaa.gov \\ ${ }^{(12)}$ National Meteorological and Oceanographic Centre, Bureau of Meteorology, GPO Box 1289, Melbourne, \\ VIC, Australia, Email: g.warren@bom.gov.au
}

\begin{abstract}
A recent workshop on in-situ wave measurement technology noted that: (1) geographical coverage of insitu data is still very limited especially as far as any measure of wave directionality is concerned, and most measurements are taken near coasts in the Northern Hemisphere; (2) present in-situ reports are not standardized resulting in impaired utility; (3) significant differences exist in measured waves from different platforms, sensors, processing and moorings. Three main topics were discussed: (1) how to add wave observing capabilities to drifting buoys; (2) how to assess and improve the quality of observations from the present networks of moored buoys; 3) the addition of wave observation capabilities to future moored buoy networks.
\end{abstract}

\section{INTRODUCTION}

Surface gravity waves entering and crossing a nation's waters, whether generated by a distant storm, local sea breeze, or a tropical storm, have a profound impact on navigation, offshore operations, recreation, safety, and the economic vitality of a nation's maritime and coastal communities. User requirements for wave information differ, from general attributes of the sea-state to frequency-directional estimates of the wave energy distribution. Long-term wave records are also important for studies of climate change and for the design of coastal and offshore structures and facilities.
Although waves are a fundamental oceanographic variable and measurement systems exist, the total number of in-situ real-time wave observations is relatively small and very unevenly distributed (Fig 1 and 2) and a limited number report some measurement of wave direction [1].

This paper describes the requirements for, and benefits of, an enhanced global wave observation network, including various in-situ observation systems and complementary remote sensing systems, both land and space-based. In particular, it describes the development of components of a global integrated ocean observing plan for waves, capable of providing the type, quantity, quality of wave observations necessary for the wide range of user applications, and maps the way forward in the next decade towards better spatial/temporal coverage from wave observing systems and a better understanding of the measurement uncertainties.

\section{WAVE DATA REQUIREMENTS}

Requirements for wave information were described in detail in the report of the OceanObs99 meeting [2] and the overall requirement and underpinning applications remain largely unchanged. Modest progress has been made towards those requirements, primarily with respect to additional moored buoy deployments along coastal margins and an increased percentage of directional wave measurements. 


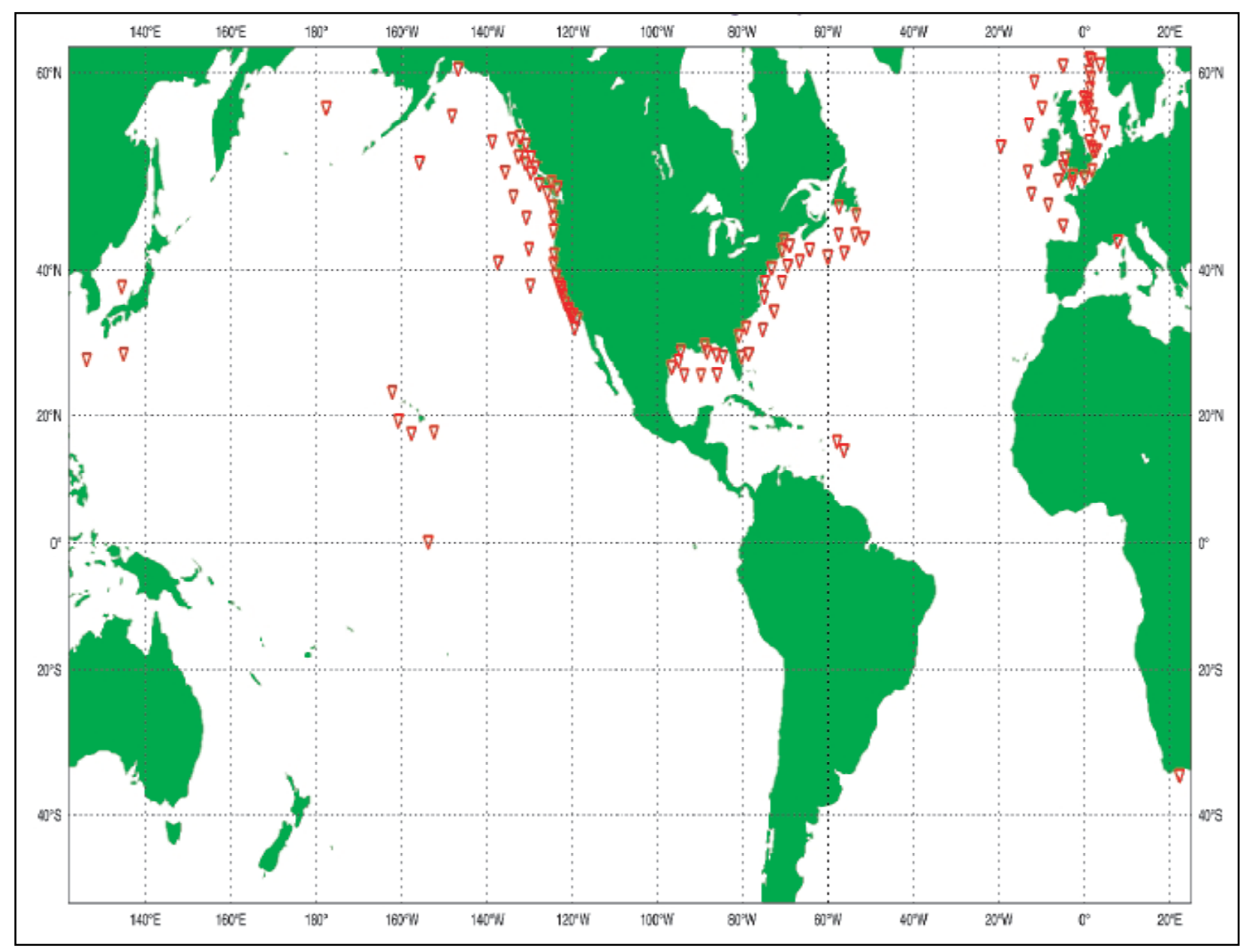

Figure 1. Fixed locations for wind and wave data regularly available on GTS in 1999, [2].

Global and regional wave observational requirements are dependent on the application and include:

(a) assimilation into wave forecast models;

(b) validation of wave forecast models;

(c) ocean wave climate and its variability on seasonal to decadal time scales; and

(d) role of waves in ocean-atmosphere coupling.

The key observations needed are: (i) significant wave height; (ii) dominant wave direction; (iii) wave period; (iv) 1-D frequency spectral wave energy density; and (v) 2-D frequency-direction spectral wave energy density. Also important are observations of individual wave components (sea/swell). In the study of ocean waves, high quality wind observations, both in-situ and remote, are often as important as the wave observations themselves.

Accuracy levels of directional wave measurements required by various user groups vary. However if the most stringent requirement is followed, then the needs of the diverse user groups and applications will be met. Tolerance requirements suggested by these groups are on the order of centimetres in amplitudes, tenths of seconds in periods, and directional estimates on the order of two to five degrees. The latter includes the higher directional moments of spread, skewness and kurtosis, which can only be successfully estimated from high-quality, 'First-5' (consisting of the first five Fourier coefficients of the spectrum) over the entire frequency range of surface gravity waves. If this requirement is set for any directional wave measurement, ground-truth would be established, analyses of these data sets would no longer require apriori assumptions for the type of device, hull design, mooring system, transfer functions used to approximate surface gravity waves.

Quantification of multi-component wave systems with differing directions at the same carrier frequency can affect various wave related applications. Here lies the paradox: numerical wave model technologies rely on wave measurements. Ultimately, wave experts rely on directional wave measurements to gain knowledge leading toward improving wave-modelling technologies. 


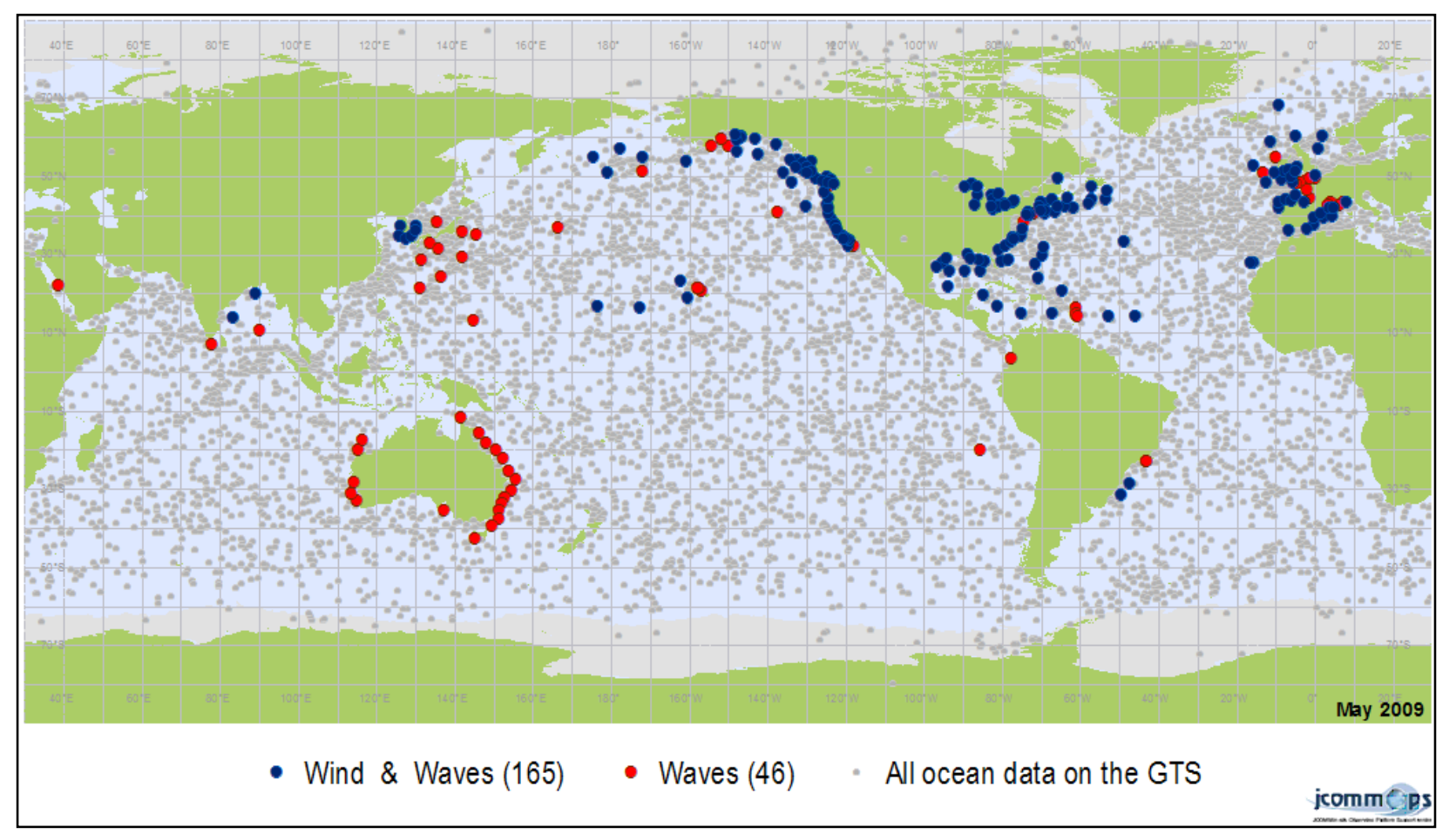

Figure 2. In-situ oceanographic observations from buoy and platforms, available on GTS, May 2009.

Historically, these improvements have relied on largescale, short-term field experiments. However, these field activities have diminished over the last decade, and so have model improvements, [3]. Increasing the number of directional wave measurements with 'First-5' capabilities will directly lead to improvements of modelling technologies and will translate into better wave forecasts for the user community.

The WMO (World Meteorological Organization) Rolling Review of Requirements and Statements of Guidance, [4] lists the wave requirements in detail for the applications described in the following paragraphs. Typically, these requirements specify significant wave height accuracy of 5-10 percent, or $10-25 \mathrm{~cm}$; wave periods of 0.1 to 1 second, wave directions to 10 degrees, and wave spectral densities to 10 percent. For certain applications, especially in coastal regions, required accuracies are higher, which presents enormous challenges.

\subsection{Assimilation into offshore wave forecast models}

Assimilation of altimeter wave height observations provide the most straightforward data used in operational wave forecast models. In-situ measurements are currently too sparse in the open ocean to be of value, but could potentially provide higher accuracy observations to complement (and correct for biases in) the satellite observations. The availability of observations with increased spatial coverage would offer significant benefits for assimilation though the ability to fully initialize features on a range of scales.
Present global model resolutions are $\sim 30-100 \mathrm{~km}$, with regional model resolutions down to $3-4 \mathrm{~km}$. Coastal models require different observing methods to those for the open ocean, due not only to their higher model resolution, but also to limitations of the satellite data close to land. Hence for these models, systems such as point-source measurements and coastal radar systems are of particular importance. The real-time nature of the application, with the rapid response time of sea state parameters to changes in winds makes timeliness a priority.

\subsection{Validation of wave forecast models}

The requirements for validation are driven by two main activities: real-time validation with requirements very similar to those for assimilation; delayed mode validation with requirements that place greater emphasis on accuracy, and relaxed timeliness requirements.

In-situ buoy data are the key data source for validation due to their accuracy the availability of spectral data, particularly for delayed mode validation. However, spatial sampling of buoy data seldom meets the requirement for validation of offshore wave models so altimeter data are also widely used. Validation studies would benefit from higher and more uniform spatial coverage of wave observations.

Validation requirements are dependent upon model resolution, though the required spatial sampling resolution is less than required for assimilation. The 
priority, is to ensure sampling is sufficient to include representative scenarios of different physical regimes globally. There is also a strong need for improved coverage of high quality spectral observations, especially to improve representation of swell in wave forecast models.

\subsection{Calibration / validation of satellite wave sensors}

While satellite instruments have the potential to provide observations with synoptic global coverage, the quality and usability of these observations is dependent upon good calibration of the sensors. This can only be achieved through use of a sufficiently dense network of accurate in-situ measurements. Such data are required for validation of altimeter wave measurements, whilst spectral data are required for use with SAR derived wave spectra.

Sampling requirements are similar to those for validation of forecast models, with the additional consideration that buoy observations located along satellite ground tracks would be of particular value. Accuracy is of greater importance than timeliness.

\subsection{Ocean wave climate and variability}

Sea state is defined as an essential climate variable (ECV) in the GCOS-92 (Global Climate Observing System) report [5]. Determination of ocean wave climate requires a long time-series of stable data, with sufficient sampling to capture the physical regimes of the global ocean. This application therefore requires sustainability of observing platforms. In-situ measurements provide the natural source for these timeseries (analyzed wave information, e.g. height period, spectra performed on a routine basis), though open ocean spatial in-situ sampling is currently inadequate for this purpose. Satellite observations can provide complementary information, but cannot be used in isolation without in-situ observations. Timeliness is not a consideration for this application.

\subsection{Role of waves in coupling}

Investigation of the role of waves in coupling requires collocated observations of a wider range of observations than is required for other applications, most notably airsea flux measurements. Spatial sampling is generally restricted to a small number of open ocean locations to allow processes to be studied in detail. This application differs from the others in that observations are generally focused campaigns rather than routine monitoring. Again, timeliness is not a consideration for this application.

\section{ELEMENTS OF A GLOBAL WAVE OBSERVING SYSTEM}

As stated in the GCOS-92 report [5], there is no sustained global observing effort at present for sea state. The best estimates of sea state for much of the world ocean are computed from model reanalysis and systems. Observing networks, satellites and analysis activities contributing to the knowledge of regional and global sea state include:

- Numerical weather prediction (analysis / reanalysis and hindcasting) systems.

- Networks of moored buoys.

- Satellite altimetry.

- Satellite Synthetic Aperture Radar (SAR).

- Voluntary Observing Ships (VOS) visual wave observations.

The minimum observation variables and their present global ocean observing systems are listed below (Tab. 1, ref SOG). The observation requirement extends beyond the minimum to include full 2-D spectral data.

\begin{tabular}{|c|c|}
\hline $\begin{array}{c}\text { Observation variables } \\
\text { (minimum) }\end{array}$ & $\begin{array}{c}\text { Observing } \\
\text { System/Platform }\end{array}$ \\
\hline \multirow{5}{*}{$\begin{array}{l}\text { Significant Wave } \\
\text { Height } \\
\text { Peak Period, and } \\
\text { 1-D Spectra }\end{array}$} & Moored Buoys \\
\hline & Satellite Altimeter \\
\hline & $\begin{array}{l}\text { Synthetic Aperture Radar } \\
\text { (SAR) }\end{array}$ \\
\hline & HF Coastal Radar \\
\hline & $\begin{array}{l}\text { Other Technologies (e.g., } \\
\text { Navigation Radar, other } \\
\text { radar, shipborne sensors } \\
\text { such as WAVEX, } \\
\text { shipboard wave recorders) }\end{array}$ \\
\hline
\end{tabular}

Table 1. Minimum requirements for observations

\section{IN-SITU WAVE MEASUREMENTS}

The majority of existing wave measurements are made in the coastal margins of North America and Western Europe, with data gaps in most of the rest of the global ocean, particularly in the southern ocean and the tropics (Fig 2, red and blue symbols), while other existing observational systems have often considerable coverage in these areas (Fig 2, grey symbols). Also, the existing sea state 'reference' moored buoys are not collocated with other ECV reference sites.

For open-water applications, the preferred wave measurement platform is a buoy. These buoys can be spherical, discus, spar, or boat-shaped hull. The most popular and widely used method measure buoy motion and converts the buoy motion into wave motion. Based on its hydrodynamic characteristics, each buoy has its own response function to characterize its motion in waves. Once the buoy motion is determined, wave motion can be derived based on the buoy's response function.

Directional buoy wave measurements based on buoy motion can be categorized into two types: translational (particle-following) or pitch-roll (slope-following) buoys. For both types, a variety of different sensor 
technologies is used to measure buoy motion. Reference [6] noted: "because directional wave information is derived from buoy motions, the power transfer functions and phase responses associated with the buoy, mooring, and measurement systems play crucial roles in deriving wave data from buoys." This dependence is particularly important at low energy levels and at both short and long wave periods where the wave signal being measured is weak and potential for added signal contamination increases.

All of the in-situ wave systems base their directional estimators on the measurements of three concurrent time series, which can be transformed into a description of the sea surface. All devices will provide good integral wave estimates (height, peak period, mean direction at the peak period, etc.). However not all sensor systems have the capability of returning high quality 'First-5' estimates because of the inherent inability of the sensor to separate wave signal from electronic and system/buoy response noise.

Existing wave measurement systems and moored buoy networks are often "legacy" systems. Standardization of sensors, system configurations, or hull type would be costly and impractical, and not necessarily desirable. This clearly points out the need for comprehensive metadata and comparability in wave measurement systems; both of these issues are dealt with further in following sections.

\section{OTHER IN-SITU WAVE OBSERVING SYSTEMS}

In-situ wave observations also include waves visually observed from VOS, which provide the longest records of wave data worldwide effectively from the mid $19^{\text {th }}$ century. For certain applications (e.g. climate variability, extreme case studies) the length of record and/or worldwide coverage of VOS wave data make them more useful than other sources of wave information. One advantage of these data is that observational practices have not changed. All visual wave reports are included in ICOADS (International Comprehensive Ocean-Atmosphere Data Set) [7] and the number of reports with wave information is close to 60 percent. After 1958, VOS reports provide separate estimates of heights, periods and directions of wind-sea and swell, making the VOS data a unique source of such information. Uncertainties in VOS wind wave heights are thoroughly described by [8] and [9].

In addition to observational uncertainties, VOS-based climatological estimates of wave characteristics suffer from inhomogeneous spatial and temporal sampling, with the largest sampling errors in the poorly observed regions of the Southern Ocean and sub-polar Northern Hemisphere. Furthermore, temporal inhomogeneity of sampling may significantly affect estimates of trends and inter-annual variability. Nevertheless accurate quality control and processing of visual data allows for the development of global climatologies of wind wave characteristics covering the period from 1958 onwards, [8]. Although visual wave data have generally poor accuracy, these data represent a substantial block of our knowledge about wind waves and should be further used and better validated.

\section{WAVE INFORMATION FROM REMOTE SENSING INSTRUMENTS}

Satellite radar altimeters provide information of significant wave height with global coverage and high accuracy. However, spatial and temporal coverage, although homogenous, and suitable along the satellite track, is still marginal orthogonal to it. Multiple altimeters are required to provide denser coverage. Long-term, stable time-series of repeat observations with high temporal resolution are needed for validation of space-borne data and climate applications.

Altimeter data have been used for more than two decades, from many different satellite platforms, including TOPEX/Poseidon, ENVISAT (Environmental Satellite), Jason, ERS-1 and 2 (European Remote Sensing satellite), for validation of hindcast and forecast model output as well as for direct real-time and wave climate uses. However, the wave estimates from satellites must be calibrated against high quality in-situ measurements to ensure accuracy and consistency. Reference [10] showed systematic differences between the altimeter wave height measurements from ERS-1, ERS-2 and ENVISAT, which must be accounted for when used in applications such as reanalysis. Well calibrated and validated altimeter wave observations remain a key component of a global wave observing program.

\section{NEW TECHNOLOGIES AND COMPLEMENTARY WAVE MEASUREMENTS}

This section recognizes the importance of emerging insitu, ground-based and space-borne technologies that will improve and complement existing wave observations. Directional wave measurements can be estimated remotely from satellites and by ground-based radars. These observations have a unique advantage over in-situ sensors, as they are able to image the entire wave field directly and over large areas. Satellite synthetic aperture radar (SAR) and Advanced Synthetic Aperture Radar (ASAR) can image the ocean surface day and night, and in all weather conditions. Present SAR sensors such as the Canadian RadarSat-1, European ERS-2 and Japanese ALOS/PALSAR (Advanced Land Observation Satellite/ Phased Array type L-band Synthetic Aperture Radar) and the European ENVISAT ASAR can provide sea surface information with $25 \mathrm{~m}$ resolutions over long strips about $100 \mathrm{~km}$ wide, or $100 \mathrm{~m}$ resolution over $500 \mathrm{~km}$ wide 
area strips [11]. New SAR sensors such as the Canadian RadarSat-2, Italy Cosmo-SkyMed (COnstellation of small Satellites TerraSAR-X for the Mediterranean basin Observation), and German TerraSAR-X can image the ocean surface at a spatial resolution as small as $1 \mathrm{~m}$. SAR systems have the capability to provide 'First-5' directional spectral estimates along large swath widths, with repeat cycles from 10 hours to two days. Real Aperture radar capability is expected to be available within 5 years.

Coastal wave applications require different observing methods to those used for the open ocean, due not only to the need for higher density coverage, but also to limitations of the satellite data close to land. For these applications, systems such as ground-based high frequency (HF) and nautical radar instruments are of particular importance. These radars provide information on significant wave height with limited coverage, good accuracy and acceptable horizontal/temporal resolution. The two primary commercially available HF radar technologies are direction finding and phased-array systems. Preliminary inter-comparisons between a phased-array radar system with directional wave buoy measurements show promise [12], [13] and [14]. Nautical radars can provide continuous directional wave properties at very high spatial resolution for ranges up to 2 to $4 \mathrm{~km}$. As these systems mature, they will complement and expand directional wave measurements.

\section{PRE-OPERATIONAL AND EMERGING TECHNOLOGIES}

Pre-operational technologies are those devices that have undergone extensive research, have been field tested beyond the "proof of concept" stage and are awaiting further evaluation prior to operational implementation. Examples of devices that fall into this category are acoustic current profilers being used to measure waves. Upward looking acoustic current profilers directly measure the pressure response of the free surface (when equipped with a pressure sensor), or follow the free surface itself (using a surface-tracking acoustic beam), and use sub-surface wave velocities computed using the Doppler shift in returns from an array of the upward looking acoustic beams. Estimates of the directional waves are constructed from these data using linear wave theory relationships to the free surface. Another example is the Air-Sea Interaction Spar, [15] buoy which provides a stable platform to measure surface fluxes and directional wave spectra.

\section{COMPLEMENTARY DATA SOURCES}

\subsection{In-situ wind data}

Wherever possible it is very advantageous to make colocated in-situ wind measurements from the same platforms as the wave measurements. This is already the case for most moored buoy wave measurements, shipboard observations and other platforms. Wind observations, are an important component of any surface reference mooring network. They provide a twoway quality control with the wave observation, and provide a necessary input to model applications to infer waves at other locations where wave measurements may not exist.

\subsection{Satellite wind data}

With few exceptions ([16]) errors in marine surface wind fields developed from conventional data remain sufficiently large to mask errors arising out of uncertainties in the physics of wave models, thereby inhibiting further progress. Satellite winds offer a potent solution to the need for reference quality forcing fields and improved wave hindcasts and forecasts. While satellite estimates of surface marine wind have long been available from passive (SSM/I (Special Sensor Microwave/Imager)) and active microwave sensors (ERS 1/2 SCAT, NSCAT (NASA's (National Aeronautics and Space Administration) Scatterometer), satellite altimeters) it was not until the launch of QuikSCAT (QS) in June 1999 with its Ku-band wideswath scatterometer that a truly global, accurate and now reasonably long term record of marine vector winds has been achieved. QS has operated long past its design lifetime and while the MetOp (Meteorological Operational Satellite) ASCAT C-band scatterometer will carry on, the impact of QS is so striking that high priority should be given to the replacement of a $\mathrm{Ku}$ band capability in space.

The dynamic range of satellite altimeter wind speeds is about half that of Ku-band scatterometers and there have been issues of sensor to sensor calibration differences and sea state effects leading to bias issues with the wind speed estimates, and, of course, the coverage is sparse; nevertheless, satellite altimeter winds can make a valuable contribution. Extreme winter storms associated with very extreme sea states, [9] can provide an important test-bed for wave model physics, [17 and 18] especially in view of the growing evidence that the relationship between wind stress and boundary layer wind speed under extreme wind forcing does not simply extrapolate from moderate wind speed conditions [19].

\subsection{Metadata}

As with any source of observational data, comprehensive metadata record is essential to properly understand the wave information originating from the different platforms, payloads and processing systems. This is necessary to understand systematic differences in the measurements from differing observing networks, and for climate applications to ensure temporal homogeneity of the records to eliminate spurious trends. The IOC-WMO (International Oceanographic 
Commission-World Meteorological Organization) Joint Commission for Oceanography and Marine Meteorology (JCOMM) has established an Ocean Data Acquisition System (ODAS) metadata standard, which is hosted at the China Meteorological Agency [20]. All agencies measuring waves from ODAS are encouraged to include their metadata in this database.

\subsection{Research requirements}

Enhancement of the future global wave observing network requires not only an increased deployment of assets, but significant research efforts to address the development of new technologies and assessment of both existing and new measurement systems. Recent discussions have focused around three main topics:

- The quality of observations from the present networks of moored buoys;

- The addition of wave observation capabilities to future moored buoy networks;

- The addition of wave observing capabilities to drifting buoys.

\subsection{Testing and evaluation}

Continuous testing and evaluation of operational and pre-operational measurement systems is an essential component of a global wave observing system, equal in importance to the deployment of new assets. The overriding objective of this evaluation is to ensure consistent wave measurements to a level of accuracy that will serve the requirements of the broadest range of wave information users. Inter-platform tests have been pursued in the past ([21] and [6]), however with the global variations in hull, sensors and processing systems, evolution of sensors, changes in buoy designs, and new platform systems, a fresh look is required. The need for this is graphically illustrated in Fig 3, and noted by recent investigations ([22] and [23]), where large systematic differences are seen between different observing networks, including a systematic 10 percent difference in significant wave height measurements between the U.S. and Canadian networks.

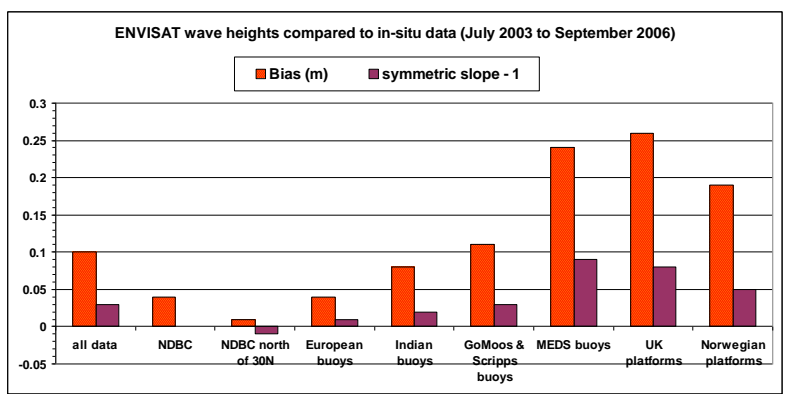

Figure 3. Discrepancies in wave observations. Bias (altimeter minus in-situ), symmetric slope (ratio of variance altimeter to variance in-situ).
In October 2008 a wave measurement technology workshop was held, [24] with broad participation from the scientific community, wave sensor manufacturers and wave data users, following on from a March 2007 Wave Sensor Technologies Workshop [25]. The overwhelming community consensus resulting from those workshops was that:

- The success of a wave measurement network is dependent in large part on reliable and effective instrumentation;

- A thorough and comprehensive understanding of the performance of existing technologies under realworld conditions is currently lacking, and

- An independent performance testing of wave instruments is required.

The workshops also confirmed the following basic principles:

- the basic foundation for all technology evaluations, is to build community consensus on a performance standard and protocol framework;

- multiple locations are required to appropriately evaluate the performance of wave measurement systems given the wide spectrum of wave regimes;

- an agreed-upon wave reference standard (e.g., instrument of known performance characteristics, Datawell Directional Waverider MK Series) should be deployed next to existing wave measurement systems for extended periods (e.g. 6-12 months, including a storm season) to conduct "in-place" evaluations of wave measurement systems.

Technically, 'First-5' refers to 5 defining variables at a particular wave frequency (or period). The first variable is the wave energy, which is related to the wave height, and the other four are the first four coefficients of the Fourier series that defines the directional distribution of that energy. At each frequency band, not only is the wave direction defined but the spread (second moment), skewness (third moment) and kurtosis (the fourth moment). The skewness resolves how the directional distribution is concentrated and the kurtosis defines the peakedness of the distribution. Obtaining these three additional parameters for each frequency band yields an improved representation of the wave field. High quality 'First-5' observations can be used to resolve two component wave systems at the same frequency, if they are at least 60 degrees apart, whereas other measurement systems cannot. Although there are more than five Fourier coefficients, the 'First-5' variables provide the minimum level of accuracy required for a directional wave observing system, as it covers both the basic information (the significant wave height, $\mathrm{H}_{\mathrm{s}}$, peak wave period, $\mathrm{T}_{\mathrm{p}}$, and the mean wave direction at the peak wave period, $\theta_{\mathrm{m}}$ ) along with sufficient detail of the component wave systems to be used for the widest 
range of activities. Figure 4 shows the application of the 'First-5' approach to compare co-located buoy wave observations.

To serve the full range of users, a wave observation network should accurately resolve the details of the directional spectral wave field as well as providing the standard integrated parameters. It is strongly recommended that all directional wave measuring devices should reliably estimate 'First 5' standard parameters.

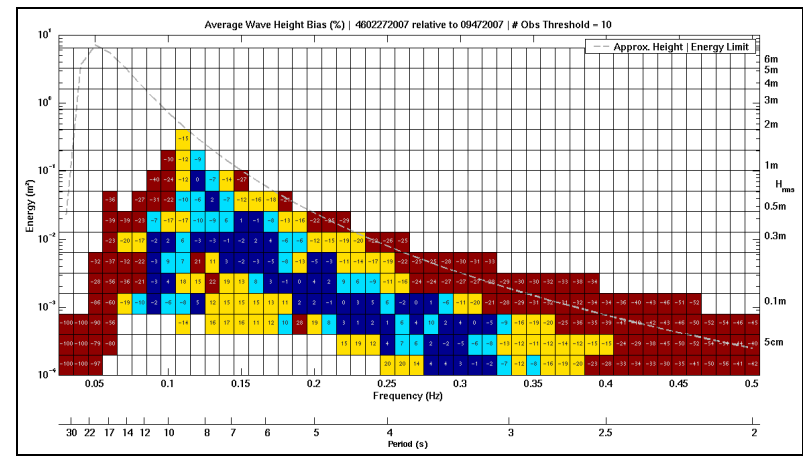

Figure 4. Comparison of energy frequency measurements for a buoy against a reference standard.

Blue indicates good agreement, red poor agreement.

\subsection{Wave observations from moored buoys}

As a result of the New York workshop [24], a Pilot Project was proposed and subsequently approved by the DBCP (Data Buoy Cooperation Panel) on Wave measurement Evaluation and Test from moored buoys (WET), with the following objectives:

- Develop the basis for an international framework for continuous testing, evaluation of existing and planned wave buoy measurements.

- Coordinate buoy inter-comparison activities.

- Develop technical documentation of differences due to hull, payload, mooring, sampling frequency and period, processing (e.g. frequency bands and cutoff), precision, transmission.

- Develop training material to educate users about how to deploy and operate wave sensors appropriately.

- Contribute appropriate material to the JCOMM Standards and Best Practice Guide.

- Establish confidence in the user community of the validity of wave measurements from the various moored buoy systems.

- Sponsor the work needed to arrive at the most promising technique.

\subsection{Wave observations from drifting buoys}

A second topic addressed during the New York workshop was the potential for development of wave measurement capabilities from drifting buoys. A drifter becomes a good wave following device when it is freely floating at the surface and not tethered to its drogue. As the number of drifters presently exceeds the original global target of 1250 , this is a potential resource for global wave measurements. Two technologies were identified that may yield high quality 2-D wave spectra from drifters: (1) downward looking ADCP (Acoustic Doppler Current Profiler) to infer 2-D spectra from wave orbital velocities; (2) GPS to measure the motion of the drifter at periods of $<100$ s.

As a result of the New York workshop [24] a Pilot Project on Wave Measurement from Drifting buoys (WMD) was proposed and subsequently approved by the DBCP, with the following objectives

- Evaluate the feasibility of wave measurement from drifters.

- Explore in particular use of GPS as a cost-effective means of yielding 2-dimensional wave spectra.

- Prove the technology by measurements and intercomparison with recognized industry standards through a careful test and evaluation program.

- In the event that good results are obtained, to sponsor the construction and deployment of up to 50 GPS wave drifters so as to develop confidence in the use of this technology.

- Establish confidence in the user community in the validity of wave measurements from drifters.

\subsection{Extending wave observing to existing systems}

The New York workshop also noted the existence of many ocean observing platforms worldwide. The OceanSITES (Ocean Sustained Interdisciplinary Time series Environment observation System [26] project expressed an interest in adding waves to the list of observables. However, taut moorings used at many of these sites are not immediately suitable for measuring waves. If such platforms are to be used, and there are very large benefits possessing wave measurement capabilities. The proposed sites could fill the needed geographical gaps in the southern ocean and mid-ocean basins [27]. Emerging technologies could be developed where buoy motions observed from GPS or ADCP systems can be applied. However, any new technologies developed must be subject to the test and evaluation procedures noted above.

The preceding sections have presented largely a global perspective on wave observing programs, or at least a general one. For regional, or national, observing systems in the coastal domain the network requirements are considerably more demanding. The range of measurement technologies will be similar, but the emphasis will be different and the density requirement 
will be higher. One approach to the network design issue to address the nearshore requirement is given in the U.S. IOOS Wave Plan [1 and 28].

\section{SUMMARY AND RECOMMENDATIONS}

This paper has described the requirements for, and benefits of, an enhanced global wave observation network based on both in-situ observation systems and also complementary remote sensing systems (both land and space-based), identified critical research requirements to develop key components of a future observing system for waves and suggested a possible scenario for regional network design.

In order to develop the proposed global wave observing system for the next decade the following recommendations are made:

- Continuity of the established buoy networks and expansion of directional measurements 'First-5' compliant is a priority both for operational and climate assessment requirements.

- Additional moorings capable of measuring waves should be deployed in data sparse areas, in particular the Southern Ocean; the proposed OceanSITES reference mooring network could provide much improved coverage.

- VOS wave data should be further used and better validated.

- A comprehensive metadata record should be developed to understand the wave information originating from different platforms, payloads and processing systems.

- $\quad$ The DBCP Pilot Projects from moored buoys WET, and WMD, efforts are essential components of the wave measurement plan and should be supported by national and intergovernmental agencies.

- Research should be conducted in development of new wave observing capabilities for observing systems that presently do not have any, in particular the OceanSITES moorings

- Address detection and documentation of possible rogue waves, and other applications, measurements of wave time series with a sampling rate of at least 1 second should be made at a subset of buoy locations and either stored on board until scheduled service visits or in some cases transmitted in real time

- Multiple satellite altimeters are required to provide denser coverage and long-term, stable time series of repeat observations with high temporal resolution.

- SAR wave measurements should be an important component of any future wave observation program
- High priority should be given to replacement of a $\mathrm{Ku}$-band scatterometer capability in space for measurement of winds.

- There is a need for development of ship-borne wave recorders and marine X-band radar systems.

\section{REFERENCES}

1. National Atmospheric and Oceanic Administration and U.S. Army Corps of Engineers, (2009). An Integrated Ocean Observing System Operational Wave Observation Plan (http://ioos.gov/program/wavesplan.html).

2. Swail, V.R., G. Komen, V. Ryabinin, M. Holt, P.K. Taylor and J. Bidlot, (2001). Waves in the Global Ocean Observation System. Observing the Oceans in the 21st Century: a Strategy for Global Ocean Observations, C.J. Koblinsky and N.R. Smith (eds), Bureau of Meteorology, Melbourne, Australia. p. 149-176.

3. The WISE Group, (2007). "Wave modeling - The state of the art," Progress in Oceanog. 75, 606-674.

4. World Meteorological Organization, Rolling Review of Requirements and Statements of Guidance, (http://www.wmo.int/pages/prog/sat/RRR-andSOG.html).

5. World Meteorological Organization, Intergovernmental Oceanographic Commission, United Nations Environment Programme, and International Council for Science, (2004). Implementation Plan for the Global Observing System for Climate in Support of the UNFCCC, WMO/TD No. 1219,

http://www.wmo.int/pages/prog/gcos/Publications/gcos92_GIP_ES.pdf

6. Teng, C.C. and R. Bouchard, (2005). "Directional wave data measured form data buoys using angular rate sensors and magnetometers," Ocean Wave Measurements and Analysis $5^{\text {th }}$ Waves 2005, ASCE, July 2005, Madrid, Spain.

7. Worley, S. J., S. D. Woodruff, R. W. Reynolds, S. J. Lubker, and N. Lott, (2005). "ICOADS release 2.1 data and products," Int. J. Climatol., 25, 823-842.

8. Gulev, S.K., V. Grigorieva, A. Sterl, and D. Woolf, (2003). "Assessment of the reliability of wave observations from voluntary observing ships: insights from the validation of a global wind wave climatology based on voluntary observing ship data," J. Geophys. Res. - Oceans, 108(C7), 3236, doi:10,1029/2002JC001437. http://www.sail.msk.ru/atlas/index.htm

9. Grigorieva, V., and S.K. Gulev, (2009). "Accuracy of the estimates of surface wind wave extremes from the visual VOS data," J. Climate, under submission.

10. Bidlot, J.-R., T. Durrant, P.Queffelou, (2008). "Assessment of the systematic differences in wave observations from moorings." JCOMM Technical Workshop on Wave Measurements from Buoys, 2 - 3 October 2008, New York, U.S. www.jcomm.info/wavebuoys. 
11. Pichel, W., (2008). "Operational implementation of SAR for U.S. government applications," Alaska

Environmental Satellite Workshop, Fairbanks, AK, http://www.gina.alaska.edu/page.xml?group=groundstati on\&page=Satellite_Workshop .

12. Voulgaris, G., B.K. Haus, P. Work, L.K. Shay, H.E. Seim, R.H. Weisberg, and J.R. Nelson, (2008). "Waves Initiative within SEACOOS," Marine Technology Society Journal, Vol 42, No. 3, 68-80.

13. Shay, L.K., H.E. Seim, D. Savidge, R. Styles, and R.H. Weisberg, (2008). "High frequency radar observing systems in SEACOOS: 2002-2007 lessons learned," Marine Technology Society Journal, Vol 42, No. 3, 5567.

14. Haus, B.K., (2007). "Surface current effects on the fetchlimited growth of wave energy," J. Geophysical Research, Vol. 112, C03003, 15pp.

15. Graber, H.C., E.A. Terrary, M.A. Donelan, W.M. Drennan, J.C. Van Leer and D.A. Peters, (2000). “ASIS A new air-sea interaction spar buoy: design and performance at sea," J. Atm. and Oceanic Tech., Vol. 17, Issue $5,701-720$.

16. Cardone, V. J., H. C. Graber, R. E. Jensen, S. Hasselmann, and M. J. Caruso, (1995). "In search of the true surface wind field in SWADE IOP-1: Ocean wave modeling perspective," The Global Atmosphere and Ocean System, 3, 107-150.

17. Holliday, N. P., M. J. Yelland, R. W. Pascal, V. R. Swail, P. K. Taylor, C. R. Griffiths, and E. C. Kent, (2006). "Were extreme waves in the Rockall Trough the largest ever recorded?," Geophysical Research Letters, 33, L05613, doi:10.1029/2005GL025238.

18. Cardone, V. J., R. E. Jensen, D. T. Resio, V. R. Swail, and A. T. Cox, (1996). "Evaluation of contemporary ocean wave models in rare extreme events: Halloween storm of October 1991; Storm of the century of March, 1993," J. of Atmos. and Oceanic Tech., 13, 198-230.

19. Donelan, M.A., B.K. Haus, N. Reul, W.J. Plant, M. Stiassnie, H.C. Graber, O.B. Brown, and E.S. Saltzman, (2004). "On the limiting aerodynamic roughness of the ocean in very strong winds," Geophys. Res. Lett. 31, L18306.

20. World Meteorological Organization, Intergovernmental Oceanographic Commission, Joint Commission for Oceanography and Marine Meteorology Ocean Data Acquisition System (ODAS) Metadata Standards, China Meteorological Agency, http://www.odas.org.cn/.

21. O'Reilly, W.A., T.H.C. Herbers, R.J. Seymour, and R.T. Guza, (1996). "A comparison of directional buoys and fixed platform measurements of Pacific Swell, J. Atm. and Oceanic Tech., Vol 13, 231-238.

22. Queffeulou P., (2006). "Altimeter wave height validation an update," OSTST meeting, Venice, Italy, March 16-18, 2006. (http://www.jason.oceanobs.com/html/swt/posters2006 uk.html).
23. Durrant, Tom H., Diana J. M. Greenslade, and Ian Simmonds, (2009). "Validation of Jason-1 and Envisat Remotely Sensed Wave Heights," J. Atm. and Oceanic Tech., Volume 26, Issue 1 (January 2009) pp. 123-134. doi:10.1175/2008JTECHO598.1.

24. Joint Commission for Oceanography and Marine Meteorology, Technical Workshop on Wave Measurements from Buoys, New York, NY, October 2008, www.jcomm.info/wavebuoys .

25. Wave Sensor Technologies Workshop, Alliance for Coastal Technologies, March 2007, www.act-us.info.

26. OceanSITES, A worldwide system of deepwater reference stations," http://www.oceansites.org/.

27. Send, U. \& Co-Authors (2010). "OceanSITES" in these proceedings (Vol. 2), doi:10.5270/OceanObs09.cwp.79

28. Jensen, R., Birkemeier, W. \& Burnett, W. (2010). "An Integrated Ocean Observing System (IOOS): A US Based Operational Wave Observation Plan" in these proceedings (Annex), doi:10.5270/OceanObs09. 